\title{
Mass production of bacterial communities adapted to the degradation of volatile organic compounds (TEX)
}

\author{
Miléna Lapertot · Chantal Seignez \\ Sirous Ebrahimi · Sandrine Delorme · \\ Paul Peringer
}

Received: 29 September 2005/ Accepted: 4 July 2006/Published online: 8 November 2006

(C) Springer Science+Business Media B.V. 2006

\begin{abstract}
This study focuses on the mass cultivation of bacteria adapted to the degradation of a mixture composed of toluene, ethylbenzene, $O$-, $m$ - and $p$-xylenes (TEX). For the cultivation process Substrate Pulse Batch (SPB) technique was adapted under well-automated conditions. The key parameters to be monitored were handled by LabVIEW software including, temperature, $\mathrm{pH}$, dissolved oxygen and turbidity. Other parameters, such as biomass, ammonium or residual substrate concentrations needed offline measurements. SPB technique has been successfully tested experimentally on TEX. The overall behavior of the mixed bacterial population was observed and discussed along the cultivation process. Carbon and nitrogen limitations were shown to affect the integrity of the bacterial cells as well as their production of exopolymeric substances (EPS). Average productivity and yield values successfully reached the industrial specifications, which were $0.45 \mathrm{~kg}_{\mathrm{DW}} \mathrm{m}^{-3} \mathrm{~d}^{-1}$ and $0.59 \mathrm{~g}_{\mathrm{DW}} \mathrm{g}_{\mathrm{C}}^{-1}$, respectively. Accuracy and reproducibility of the obtained results present the controlled SPB process as a feasible technique.
\end{abstract}

M. Lapertot $(\varangle) \cdot$ C. Seignez $\cdot$ S. Ebrahimi .

S. Delorme $\cdot$ P. Peringer

Laboratory of Environmental Biotechnology, ENAC,

Ecole Polytechnique Fédérale de Lausanne (EPFL),

Station 6, CH-1015 Lausanne, Switzerland

e-mail: milena.lapertot@epfl.ch
Keywords Automated process .

Biodegradation $\cdot$ BTEX $\cdot$ Kinetics $\cdot$ Metabolic adaptation $\cdot$ Stripping

\section{Introduction}

Toluene, ethylbenzene, and xylene (TEX) are among the most important contaminants present in surface and groundwater which usually originate from the leakage of tanks containing petroleum-derived products and industrial wastewaters (Acuna-Askar et al. 2003). Because they are both toxic and relatively water soluble compared with other petroleum constituents, their entry into surface and drinking water is of major concern. In spite of governmental intervention in many countries, their emission to the environment is still escalating. Therefore, there is a need to develop and optimize technologies for removing TEX from groundwater, especially when downstream drinking water resources are a concern. Among all remediation technologies for treating TEX-contaminated groundwater, bioremediation appears to be an economical, energy-efficient and environmentally sound approach. Microorganisms are able to degrade TEX under aerobic, microaerobic or hypoxic, as well as anaerobic conditions (Villatoro-Monzon et al. 2003). Development and upgrading of the biotechniques for simultaneous and efficient 
removal of all TEX with a mixed culture are of major challenges.

The substrate pulse batch (SPB) technique is attractive for the production of a specialized biomass used to inoculate biosystems which treat volatile organic compounds (VOCs). The SPB technique is a batch cultivation process in which substrates are supplied in pulses. This technique can be considered as a special limit case of a conventional, semi-continuous extended culture operation: total volume remains virtually constant because substrate is fed in a gaseous, solid or very concentrated liquid form, according to an intermittent profile (Lapertot et al. 2005).

This technique aims to save both heterogeneity and kinetic dynamics of the mixed population thanks to the continual variation of substrate concentration in the medium. Short contact times due to rapid degradation also avoid toxic damages which may result from the solvent effects onto bacterial cells (De Bont 1998). This process is recommended for achieving a more stable and efficient biomass culture (León et al. 1999; Seignez et al. 2001). However, industrial implementation of the SPB technique is still restricted due to a limited controllability. This work proposed criteria to develop and automate the control.

This study was aimed to improve the productivity and yield of a particular microbial culture for degrading a TEX mixture using the SPB technique. This research was in context of an European Project, "Bioreactor For Innovative Mass Bacteria Culture, BIOMAC" (see: www.eureka.be, project E!2497). This study presents the kinetics of an adapted bacterial consortium to degrade TEX in an automated bioreactor using the SBP technique.

\section{Materials and methods}

\section{Inoculum preparation}

The bacterial consortium used to inoculate the bioreactor was selected in our laboratory in a previous work (León et al. 1999). The bacteria were originally isolated from the sludge of a wastewater treatment plant (Novartis and Rohner AG, Basel, Switzerland) and from the biotrickling filters (Rohner AG, Basel, Switzerland), adapted to the TEX degradation and cultivated on TEX or toluene as sole source of carbon then preserved at $-80^{\circ} \mathrm{C}$. A sample of this adapted mixed culture was cultivated in flasks containing nutrient medium (CM67, Oxoid LTD, Basingtoke, England) at $30^{\circ} \mathrm{C}$ for 1 day. Then the obtained biomass was collected by centrifugation and transferred into the batch reactor. The nutrient medium consisted of inorganic salts and vitamins necessary for the growth of microorganisms, the same composition as previously reported (León et al. 1999) with ammonium as the nitrogen source. In all the experiments, the sole carbon and energy source consisted of $90 \%$ (v/v) toluene (Tol), 2.5\% ethylbenzene (EB), $6.5 \% m$ - and $p$-xylenes (X), $1.3 \% o$-xylene. This mixture is called "TEX". The rationale corresponded to the industrial specifications and represented a typical contaminated stream. Compounds were supplied by Fluka, Buchs, Switzerland. Experiments were made under non-sterile conditions. TEX were supplied by a precision feeding pump (SpectraPhysics, San José, USA).

Bioreactor and automation program

The experimental set-up used in this study is presented in Fig. 1. The bioreactor is made of stainless steel and Pyrex glass; with a total volume of $14.5 \mathrm{l}$. The working liquid volume was $10 \mathrm{l}$. Numerous ports along its height and at the bottom allow feeding, sampling and connecting the measuring probes. The characteristics of the reactor and the operating conditions for the experiments are described in Table 1. It should be noticed that during the process, the viscosity of the medium increased. Therefore, agitation and aeration rates were stepwise increased to avoid oxygen-limiting conditions.

The overall set-up was controlled by the socalled BioOPT program. This LabVIEW computer-based monitoring program allows data acquisition and was used to optimize the biodegradation process. The advantage of the BioOPT program leans more on its flexibility than on its analytical properties. Modulable FieldPoints (National Instruments) were the connecting tools between computer and instrumental systems. 
Fig. 1 Schematic presentation of the laboratory bioreactor

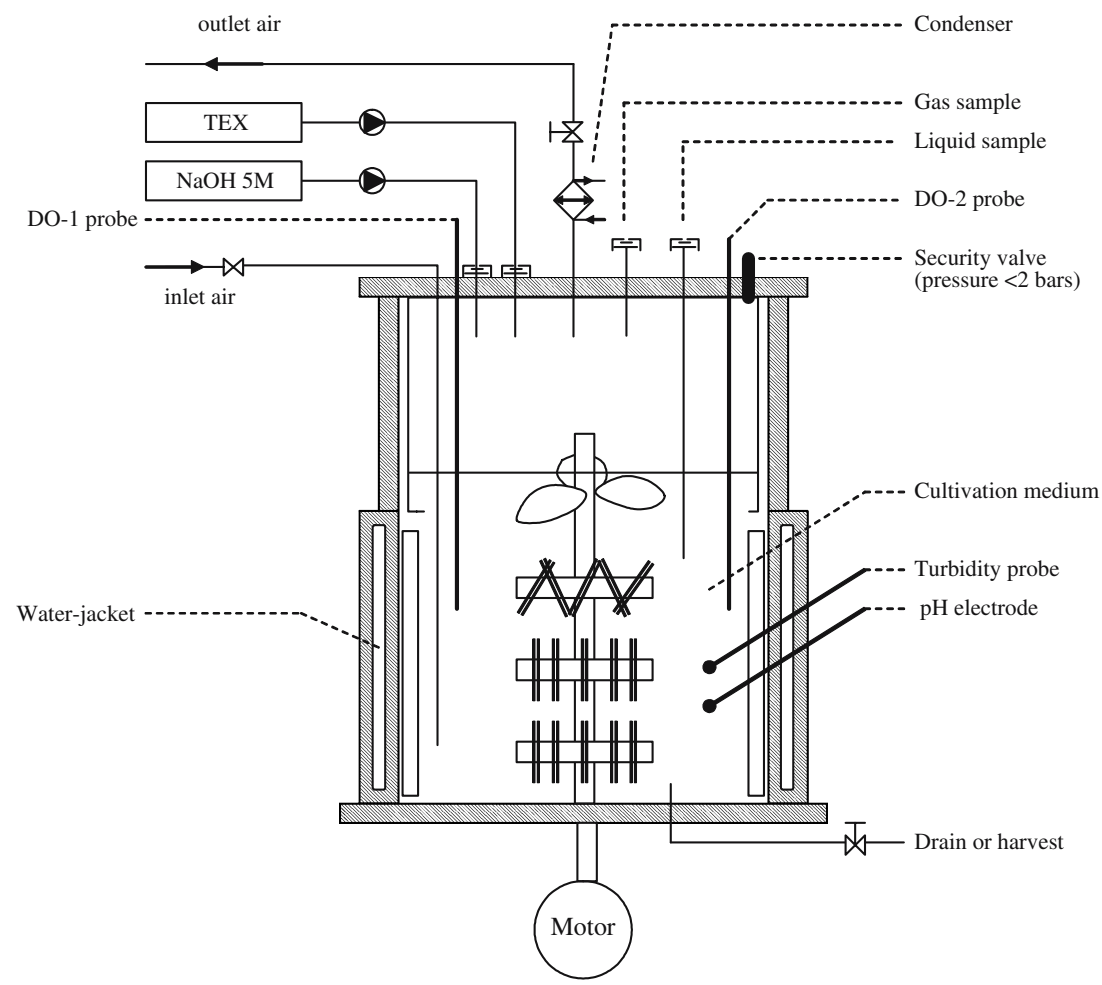

Volatile Organic Compounds (VOCs) lost by stripping were continuously quantified by FID analyses during the process. The amounts were systematically taken into account for any calculation of the TEX conversion rate.

Dissolved organic carbon concentration was measured by an IR detector Shimadzu TOC-500 (Burkard Instrumente, Switzerland). The reactor sample was filtrated at $0.45 \mu \mathrm{m}$ (Schleicher\&Schuell, Germany), acidified by $\mathrm{HCl} 2 \mathrm{M}$ and the $\mathrm{CO}_{2}$ was purged before analysis.

Metabolite estimation (aromatic compounds) was made by measuring the optical density of the filtered sample at $255 \mathrm{~nm}$ in an UV spectrophotometer (Hitachi U-2000, Tokyo, Japan). Ammonium and nitrate in the liquid phase of the batch

Table 1 Operational data for the bioreactor

\begin{tabular}{lll}
\hline Parameter & Value & Material \\
\hline Temperature & $35 \mathrm{C}$ & PT 100, Digital thermostat \\
PH & $6.5-7$ & Electrode, Liquisys S, Threshold contact \\
Dissolved oxygen (DO) & $0.8-98 \% 100 \%=7.1 \mathrm{mg} \mathrm{l}^{-1}$ & Oximetric probe $(L=31.7 \mathrm{~cm})$ Ingold Messtecknick \\
Agitation & $170-800 \mathrm{rpm}^{*}$ & Motor:Lust \\
Aeration & $0.5-0.7 \mathrm{~min}^{-1}, K_{\mathrm{La}}=3-9 \mathrm{~h}^{-1}$ & Brooks instrument \\
\hline
\end{tabular}

*Agitation started at $170 \mathrm{rpm}$ and was stepwise increased to final value of $800,3.75 \%$ per day 
reactor were determined by the enzymatic method (Boehringer, Manheim, Germany) to control the nitrogen measurement for TEX degradation.

The biomass concentration was monitored by dry-weight measurement and by absorbance at $650 \mathrm{~nm}$.

The LIVE/DEAD ${ }^{\circledR}$ BacLight $^{\mathrm{TM}}$ Bacterial Viability Kit L-7007 (Molecular Probes Corporation, Canada) provides a quantitative index of bacterial viability. It uses a mixture of $\mathrm{SYTO}^{\circledR} 9$ green fluorescent nucleic acid stain which labels bacteria with both intact and damaged membranes. Besides, the red fluorescent nucleic acid stain Propidium Iodide penetrates only bacteria with damaged membranes. The bacterial samples were centrifuged and filtered through $0.2 \mu \mathrm{m}$ PC Memb 13 mm (Nuclepore CORP., Canada). The Epi-FluoroMicroscopic observation was carried out under UV light with emission filters BP 450$490 \mathrm{~nm}$, reflector FT 510 and stop-filter LP 520 (Eclipse 800, Nikon, Switzerland).

Extracellular polymeric substances (EPS) were extracted as follows. Samples of the culture $(10 \mathrm{ml})$ were centrifuged at $16,000 \times g$ for $30 \mathrm{~min}$ at $4^{\circ} \mathrm{C}$. The supernatant polysaccharides (dissolved EPS) were isolated by precipitation with 3 volumes of ethanol, and kept overnight at $4{ }^{\circ} \mathrm{C}$ (Duenas et al. 2003). The pellets (bound EPS + bacteria) were resuspended in nutrient medium containing 10 mM EDTA (Platt et al. 1985). After sedimentation of the bacterial cells by centrifugation, the supernatant was treated as for the dissolved EPS. After centrifugation of both bound- and dissolvedEPS tubes $\left(5,000 \times g, 20 \mathrm{~min}, 4^{\circ} \mathrm{C}\right)$, the pellets were dispersed in aqueous $80 \%$ ethanol and centrifuged again (3 times). The final precipitates were dissolved in distilled water $(50 \mathrm{ml})$. The carbohydrate content was determined by the Anthrone method modified from Standard Methods (Raunkjauer et al. 1993) with glucose as the standard. The determinations were done in triplicate and the average values were calculated with less than $5 \%$ standard deviation.

\section{Results and discussions}

To optimize the production of adapted bacteria able to degrade TEX according to industrial specifications, the cultivation of a bacterial community was carried out under different operational conditions and kinetics features were followed.

\section{Microbial growth}

Several cultivations were carried out in order to automate the process. Indeed the key point was to meet a convenient relation between (i) the amount of solvents which are the carbon source and (ii) their toxic effects, which inhibit the bacterial growth. For cultivation process SPB was adapted. The SPB technique allows the bacteria to degrade a low amount of the initial molecule into less toxic metabolites. Each pulse of substrate favors the bacterial growth and the acclimation to the solvents. Higher substrate amounts are progressively introduced into the biological system. It was shown that low amounts of TEX (326 $\mathrm{mg} \mathrm{l}^{-1}$ every $2 \mathrm{~h}$ during 6 days) were necessary to acclimate bacteria to TEX. After this step, the shorter the lag phase, the more resistant the bacterial consortium to high substrate loading (696 mg $\mathrm{l}^{-1}$, or injection volume of $0.8 \mathrm{ml} \mathrm{l}^{-1} \mathrm{ev}$ ery $5 \mathrm{~min}$ for instance).

Evolution of biomass concentration and substrate mass conversion rate during the overall production process were investigated: $23 \mathrm{~g} \mathrm{l}^{-1}$ of biomass was produced within 17 days. During this period approximately 0.81 of TEX mixture was injected into the biological system. Increase of TEX injection was progressive and has depended of the biomass production. Average increase has been $0.1 \mathrm{ml} \mathrm{l}^{-1} \mathrm{~d}^{-1}$. According to the carbon contents of the off-gases which were continuously measured (FID analyses), 6.5\% of the loaded TEX was stripped. Total biomass yield and biomass productivity were estimated to be $0.3 \mathrm{~g}_{\mathrm{DW}} \mathrm{g}_{\mathrm{TEX}}{ }^{-1}$ and $0.06 \mathrm{~g}_{\mathrm{DW}} \mathrm{l}^{-1} \mathrm{~h}^{-1}$, respectively.

The obtained results indicate that using the SPB method under automated conditions (computer control) gives at least similar results to those obtained with an operator's supervision (unpublished results). The operator was managing both the injected amount of TEX and the time allowed for the bacteria to degrade the substrate. The above-mentioned values show $10 \%$ improvement compared with manual controlled-conditions. In 
fact the acclimation was minimized in order to reduce the lag phase and to limit inhibition.

Specific growth rates $\left(\mu_{\max }\right)$ were calculated to be about $0.007 \mathrm{~h}^{-1}$. Overall, calculated growth rates ranged between 0.003 and $0.011 \mathrm{~h}^{-1}$ depending on carbon or nitrogen contents in the nutrient medium. These values are comparable with other reports. For instance Shim and Yang (1999) have reported that specific growth rates ranged between 0.001 and $0.002 \mathrm{~h}^{-1}$ with only toluene or $o$-xylene as substrate.

After the initial period of induction (6 days) and during 30 days of cultivation, interval of time between successive pulses was reduced from $1.5 \mathrm{~h}$ to $0.5 \mathrm{~h}$. Besides and alternatively to the higher frequency of pulses, the amounts of TEX were also increased from an initial concentration in the liquid phase of $24 \mathrm{mg}_{\mathrm{c}} \mathrm{l}^{-1}$ until a final concentration of $67 \mathrm{mg}_{\mathrm{c}} \mathrm{l}^{-1}$ (stripping losses already subtracted). Therefore average productivity and yield values reached $0.45 \mathrm{~kg}_{\mathrm{DW} \mathrm{m}} \mathrm{m}^{-3} \mathrm{~d}^{-1}$ and $0.59 \mathrm{~g}_{\mathrm{DW}} \mathrm{g}_{\mathrm{c}}^{-1}$, respectively. These data come up to the industrial specifications and confirm the benefits of such an improved technology.

Impact of $\mathrm{C}$ and $\mathrm{N}$ concentration on cell viability

The cellular viability was investigated during the cultivation process. After inoculation, the ratio of healthy cells was approximately $50 \%$. It reached a climax $(90 \%)$ after $24 \mathrm{~h}$ and then progressively decreased to $60 \%$ within 16 days. Besides, it was shown that limiting the amounts of carbon and nitrogen provoked cellular damages and was concomitant with a lower productivity. This effect was reversible, since higher $\mathrm{N}$ and $\mathrm{C}$ loadings allowed the cells to recover their integrity: this bacterial property is called resilience.

Exo-Polymeric Substances (EPS) were also studied at different cultivation conditions.
Table 2 shows that limiting $\mathrm{C}$ or $\mathrm{N}$ contents of the nutrient medium change both the composition and the total amount of EPS. For instance, when the $\mathrm{C}$ source was limiting, the total amount of EPS was twice the amount measured with the adequate supply of $\mathrm{C}$ and $\mathrm{N}$. Besides, limiting $\mathrm{N}$ provoked an increase of carbohydrates contents ( $92 \%$ instead of $40 \%$ with balanced $\mathrm{C}$ and $\mathrm{N}$ contents in the nutrient medium). Since EPS are predominantly composed of carbohydrate and protein, the ratio between each constituent depends on the relative $\mathrm{C}$ and $\mathrm{N}$ amounts in the nutrient medium. Their active secretion is also linked to the environmental conditions: carbon starvation provokes the production of dissolved EPS as a response to an energetic deficiency. On the contrary, a nitrogen limited culture tends to minimize the overall EPS production and certainly favors its consumption. The similar link between nutrients, bacterial viability and growth has been demonstrated by Durnaz and Sanin (2001) and Liu and Fang (2003).

\section{Substrate conversion}

Three steps can be distinguished during elimination of TEX after injection into the liquid phase: (1) fast removal of TEX, followed by an increase of oxygen consumption rate during the first 15 min, (2) slower removal of TEX and stabilization of DO (lower bacterial consumption), (3) no residual concentration of TEX, significant increase of both $\mathrm{DO}$ and $\mathrm{A}_{255}$ (absorbance at $255 \mathrm{~nm}$ ). This step should correspond to the exportation of intermediate metabolites (León et al. 1999) (Fig. 2).

Such studies were carried out during 30 days of process and focused on the removal of each compound separately (Tol, EB, o-, $m-, p-\mathrm{X}$ ). They revealed some modifications of the bacterial behavior in the course of cultivation. As illustrated
Table 2 Influence of $\mathrm{C}$ and $\mathrm{N}$ on the cellular metabolism of the mixed population

\begin{tabular}{llll}
\hline Conditions & Limiting C & Limiting N & Balanced C and N \\
\hline Viability & $30 \%$ & $50 \%$ & $65 \%$ \\
Dissolved EPS & $2.5 \mathrm{~g} / \mathrm{g}_{\mathrm{DW}}$ & $0.2 \mathrm{~g} / \mathrm{g}_{\mathrm{DW}}$ & $1.0 \mathrm{~g} / \mathrm{g}_{\mathrm{DW}}$ \\
$\quad$ Carbohydrates contents & $40 \%$ & $2 \%$ & $40 \%$ \\
Bound EPS & $0.8 \mathrm{~g} / \mathrm{g}_{\mathrm{DW}}$ & $0.1 \mathrm{~g} / \mathrm{g}_{\mathrm{DW}}$ & $0.5 \mathrm{~g} / \mathrm{g}_{\mathrm{DW}}$ \\
$\quad$ Carbohydrates contents & $25 \%$ & $67 \%$ & $40 \%$ \\
\hline
\end{tabular}




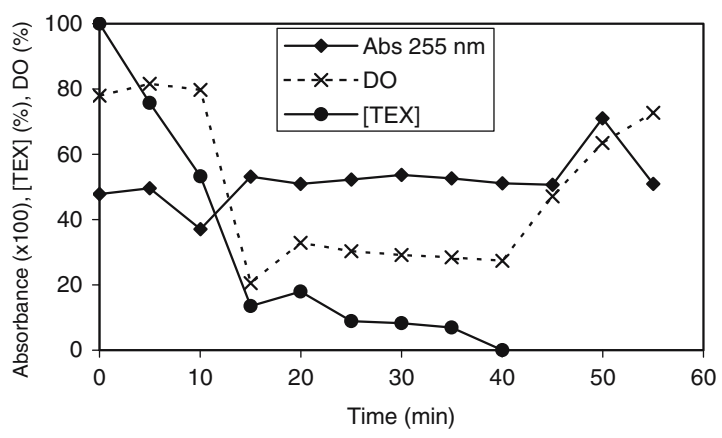

Fig. 2 Disappearance ratio (\%) of TEX, oxygen uptake and $\mathrm{A}_{255}$ evolution during a representative pulse, after 4 days of cultivation. $[\text { TEX }]_{10}=25 \mathrm{mg}_{C} / 1,[X]=0.85 \mathrm{~g} \mathrm{l}^{-1}$, Agitation $=200 \mathrm{rpm}, Q_{\text {air }}=0.51 \mathrm{~min}^{-1}$

in Fig. 3, from day 1 until day 20, toluene exhibited the fastest elimination. It was followed by EB, $m$ - and $p$-X, and finally $o$-X. (Fig. 3a, b). Between days 22 and 25, this ranking was changed: EB reached first the lowest residual concentration and Tol was only removed after Xylenes (Fig. 3c). Then from day 26 until the end, the ranking was the same as at the beginning (Fig. 3d). For all that, global rates of TEX disappearance remained unchanged (see Fig. 4 below). Similar evolutions were observed thrice.

Three points are tentatively proposed to comment the differences in the TEX removal. First, as the substrate loading is continuously accommodated to the biomass growth, it is reasonable to consider the saturation and full expression of available enzymes (Grady et al. 1996). Since global degradation and growth parameters remain constant (see Fig. 4 below), sporadic delays between supply and demand would only tend to orientate the metabolic activity towards the EPS production. Second, the greater the amounts of TEX injected in the medium, the higher its overall toxicity. Solvents are known to accumulate in and disrupt the bacterial cell membrane thus affecting the structural and functional integrity of the cell (Sikkema et al. 1995). Therefore the major metabolic pathway could be changed. Indeed two distinct substrate interactions are to be considered: Tol and EB are inhibitive competitors, whereas Xylenes transformation is necessarily cometabolic and so secondary to Tol and/or EB degradation (Yu et al. 2001a, b). Three, the studied biodegradation is carried out by a mixed bacterial community. Many strains are involved, and their proportion can be modified as well as the metabolic dynamism during the cultivation process. Biomolecular techniques such as RT-PCR (Real Time Polymerase Chain Reaction) or T-RFLP (Terminal Restriction Fragment Length Polymorphism) would provide an idea of the bacterial composition as the process goes along.
Fig. 3 Disappearance of TEX checked along 30 days of cultivation
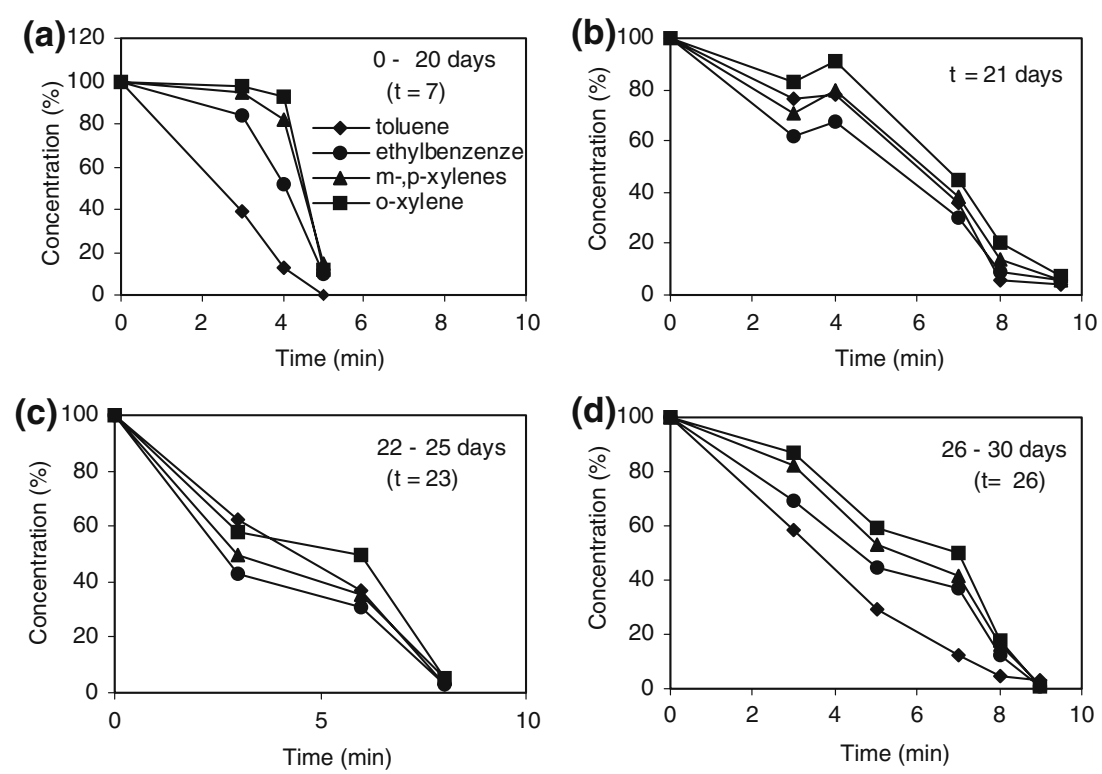
Fig. 4 Evolution of the degradation rates $q_{\mathrm{s}}$ during the cultivation process

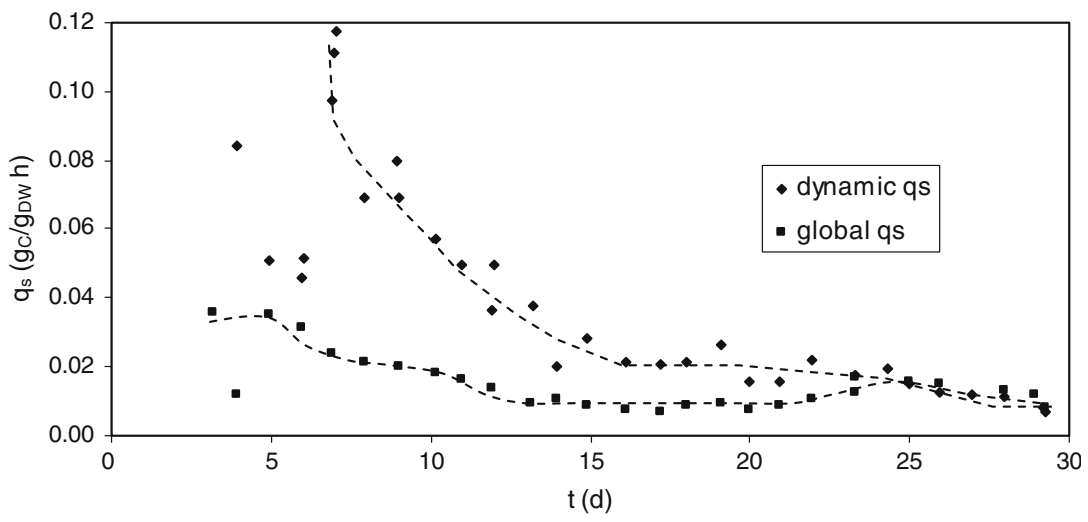

Substrate uptake rate

TEX degradation rates were investigated during the overall process. The initial substrate uptake rate $\left(q_{\mathrm{s}, \mathrm{i}}\right)$ is calculated from the slope of the time course of the TEX removal from the gas phase (GC analyzes). Only the first $15 \mathrm{~min}$ after injection of TEX were considered for this calculus. Global substrate uptake rate $\left(q_{\mathrm{s}, \mathrm{g}}\right)$ was calculated based on the total amount of TEX removed during one pulse (by correcting for stripping). As $q_{\mathrm{s}, \mathrm{g}}$ also took into account the degradation of both TEX and intermediate metabolites, it was lower than the initial rate $\left(q_{\mathrm{s}, \mathrm{i}}\right)$. Figure 4 shows the typical time course of the substrate uptake rates during the cultivation process.

Both substrate uptake rates were maximal at the beginning of the cultivation process and sloped down to a mean value of $0.015 \mathrm{~g}_{\mathrm{c}} \mathrm{g}_{\mathrm{DW}}^{-1} \mathrm{~h}^{-1}$. It should be noticed that the substrate uptake rate presents the rate of removal of the TEX from the gas phase. However it is difficult to argue if the substrate is either degraded or only absorbed inside the bacterial cell. Therefore decreasing $q_{\mathrm{s}}$ reflects a metabolic inhibition and/or an increasing difficulty for the bacteria to incorporate the substrate. The same behavior has also been reported by Bielefeldt and Stensel (1998a, b), the longer the cultivation time, the lower the degradation rates during the cultivation process. A progressive deterioration of the bacterial walls is prospected to explain this evolution, which is due to the wellknown toxicological characteristics of the lipophilic substrates. In this case, to accelerate the adaptation phase, the most efficient conditions have to be selected. A more stable process can be achieved quickly which improves the overall biomass productivity. Further experimentation including enzymatic studies should be necessary to confirm these statements.

\section{Conclusion}

In this study, the SPB technique has been adopted for the cultivation of bacteria for degradation of TEX. Obtained results indicated that relatively higher yields and productivity could be achieved in computer controlled SPB technique compared to the manually controlled one. Automated SPB cultivation technique benefits form an easier maintenance coupled with improved performances. The subsequent increase of reliability presents this process as a ready-way to produce large quantities of cell mass. Microorganisms produced in this way can play a major role for the removal of hydrocarbons from industrial off-gases, degradation of substitute organic solvents, reduction in odors from wastewater plants and the food industry or even the removal of pollutant mixtures containing chlorinated solvents.

Acknowledgements The authors wish to thank the European Commission for financial support under the EUREKA project, "Bioreactor For Innovative Mass Bacteria Culture, BIOMAC"' (see: www.eureka.be, project E!2497), as well as the CADOX Project (contract no. EVK1-CT-2002-00122). 


\section{References}

Acuna-Askar K, Englande AJ Jr., Ramirez-Medrano A, Coronado-Guardiola JE, Chavez-Gomez B (2003) Evaluation of biomass production in unleaded gasoline and BTEX-fed batch reactors. Wat Sci Technol 48(8):127-133

Bielefeldt A, Stensel H (1999a) Evaluation of biodegradation kinetic testing methods and longterm variability in biokinetics for BTEX metabolism. Wat Res 33(3):733-740

Bielefeldt A, Stensel H (1999b) Modeling competitive effects during biodegradation of BTEX mixtures. Wat Res 33(3):707-714

De Bont J (1998) Solvent-tolerant bacteria in biocatalysis. Tibtech 16:493-499

Duenas M, Mundate A, Perea A, Irastorza A (2003) Exopolysaccharides production by Pedioceccus damnosus 2.6 in a semi defined medium under different growth conditions. Int J Food Microbiol 2709:1-8

Durnaz B, Sanin F (2001) Effects of carbon nitrogen ratio on the composition of microbial extracellular polymers in activated sludge. Water Sci Technol 44(1):221-229

Grady L, Smets B, Barbeau D (1996) Variability in kinetic parameter estimates: a review of possible causes and a proposed terminology. Wat Res 30(3):742-748

León E, Seignez C, Adler N, Péringer P (1999) Growth inhibition of biomass adapted to the degradation of toluene and xylenes in mixture in a batch reactor with substrates supplied by pulses. Biodegradation 10:245250

Lapertot M, Domeniconi P, Seignez C, Ebrahimi S, Peringer P (2005) Upgraded conventional cultivation techniques for the mass production of bacterial communities adapted to the degradation of Volatile Organic Compounds (TEX). Congress on Biotech- niques for Air Pollution Control. La Coruña, Spain. In press

Liu H, Fang H (2003) Influence of extracellular polymeric substances (EPS) on flocculation, settling and dewatering of activated sludge. Crit Rev Env Sci Technol 33(3):237-273

Platt R, Geesey G, Davis J, White D (1985) Isolation and partial chemical analysis of firmly bound exopolysaccharides from adherent cells of fresh eater sediment bacterium. Can J Microbiol 31:675-680

Raunkjaer K, Hvitved-Jacobsen T, Nielsen P (1993) Measurement of pools of protein, carbohydrates and lipid in domestic wastewater. Wat Res 28:251-262

Seignez C, Vuillemin A, Adler N, Péringer P (2001) A procedure for production of adapted bacteria to degrade chlorinated aromatics. J Hazard Mater B 84:265-277

Shim H, Yang S (1999) Biodegradation of benzene, toluene, ethylbenzene, and $o$-xylene by a coculture of Pseudomonas putida and Pseudomonas fluorescens immobilized in a fibrous-bed bioreactor. J Biotechnol 67(2-3):99-112

Sikkema J, De Bont J, Poolman B (1995) Mechanisms of solvent toxicity of hydrocarbons. Microbiol Rev 269:8022-8026

Villatoro-Monzón WR, Mesta-Howard AM, Razo-Flores E (2003) Anaerobic biodegradation of BTEX using $\mathrm{Mn}(\mathrm{IV})$ and $\mathrm{Fe}(\mathrm{III})$ as alternative electron acceptors. Water Sci Technol 48(6):125-131

Yu H, Kim B, Rittmann B (2001a) A two-step model for the kinetics of BTX degradation and intermediate formation by Pseudomonas putida F1. Biodegradation 12(6):465-475

Yu H, Kim B, Rittmann B (2001b) The roles of intermediates in biodegradation of benzene, toluene, and p-xylene by Pseudomonas putida F1. Biodegradation 12(6):455-463 